\title{
Hydrothermal synthesis of hydroxyapatite nanoparticles and their protein adsorption behavior
}

\author{
Fukue NAGATA, ${ }^{*}$ Yoshihiro YAMAUCHI, ${ }^{*, *}$ Masahiro TOMITA ${ }^{* *}$ and Katsuya KATO ${ }^{* \dagger}$ \\ *National Institute of Advanced Industrial Science and Technology (AIST), \\ 2266-98 Anagahora, Shimoshidami, Moriyama-ku, Nagoya 463-8560, Japan \\ **Division of Chemistry for Materials, Graduate School of Engineering, Mie University, \\ 1577 Kurimamachiya-cho, Tsu 514-8507, Japan
}

\begin{abstract}
Protein adsorption on hydroxyapatite particles with different morphologies was investigated. The nano-sized hydroxyapatite (nano-HAp) was prepared using calcium nitrate tetrahydrate $\left[\mathrm{Ca}\left(\mathrm{NO}_{3}\right)_{4} \cdot \mathbf{4} \mathrm{H}_{2} \mathrm{O}\right]$ and diammonium hydrogen phosphate $\left[\left(\mathrm{NH}_{4}\right)_{2}\right.$ $\left.\mathrm{HPO}_{4}\right]$ by using a hydrothermal method with varying synthesis temperature and $\mathrm{pH}$ conditions. The adsorption properties of proteins onto nano-HAp were studied using three types of proteins: bovine serum albumin (BSA, an acidic protein), myoglobin (MGB, a neutral protein), and lysozyme (LSZ, a basic protein). The adsorption amount of BSA and LSZ per unit specific surface area of nano-HAp increased as the crystallinity improved. In contrast, the improvement in the crystallinity of HAp decreased adsorption affinity to MGB. This adsorption behavior on nano-HAp would be considered by the specific binding of the $C$ - or $P$ site on HAp towards acidic or basic proteins, respectively.
\end{abstract}

(๑2013 The Ceramic Society of Japan. All rights reserved.

Key-words : Hydroxyapatite, Hydrothermal synthesis, Protein adsorption, Nanoparticles, Crystallinity

[Received May 14, 2013; Accepted July 17, 2013]

\section{Introduction}

Hydroxyapatite $\left[\mathrm{Ca}_{10}\left(\mathrm{PO}_{4}\right)_{6}(\mathrm{OH})_{2} ; \mathrm{HAp}\right]$ has attracted immense interest in recent years for various applications such as orthopedic and dental materials, as a packing column material for affinity chromatography in order to separate various proteins, as well as an inorganic support for immobilized metal catalysts. ${ }^{1)-3)}$ The crystalline and morphological controls of synthesized HAp crystals are gaining considerable importance for their utility as general adsorbents, affinity chromatographic solid supports, drug delivery system, and protein carriers. ${ }^{4-6)}$ The crystal system of HAp is hexagonal, and therefore its crystal has two crystal faces: the $a$ - and $c$-face. Several studies examining protein adsorption on HAp have reported that different types of proteins adsorb on the different crystal faces of HAp. ${ }^{7)-10)}$ The $a$-face has a positively charged site (C-site) composed of two screw-axis calcium $\left(\mathrm{Ca}^{2+}\right)$ ions. Therefore, negatively charged proteins tend to adsorb on the $a$-face. In contrast, the $c$-face has a negatively charged site (P-site) composed of oxygen ions belonging to the three phosphate groups $\left(\mathrm{PO}_{4}{ }^{3-}\right)$. Therefore, positively charged proteins tend to adsorb on the $c$-face. ${ }^{7)}$

HAp can be synthesized by various methods such as a solidstate reaction, ${ }^{11)}$ co-precipitation, ${ }^{12)}$ the sol-gel method, ${ }^{13), 14)}$ and sputtering. ${ }^{15)}$ In particular, hydrothermal methods using elevated temperatures and pressures in aqueous solutions enable us to synthesize defect-free HAp crystals with a certain shape and high crystallinity. ${ }^{16-18)}$ Therefore, by hydrothermally synthesizing HAp particles, we are able to estimate their adsorption ability for different types of proteins with greater clarity.

Many researchers have reported the relationships between HAp properties and protein adsorption behavior. Kandori et al. have

Corresponding author: K. Kato; E-mail: katsuya-kato@aist.go.jp previously reported on the influence of the HAp texture on the adsorption of bovine serum albumin (BSA). ${ }^{19}$ They have also reported that hydroxyapatites modified with pyrophosphoric acid improved protein adsorption, and the effects of pyrophosphoric branches were further evaluated. ${ }^{20), 21)}$ Kawachi et al. and Takahashi et al. have reported that rod-shaped HAp crystals synthesized hydrothermally showed a high adsorption ability for the albumin. ${ }^{22), 23)}$ Fujii et al. and Dasgupta et al. have reported on the selective protein adsorption properties of zinc-containing hydroxyapatite crystals. ${ }^{24), 25)}$ As described above, the protein adsorption capacity was investigated using various types of HAp particles, modified by organic molecules or substituted with other types of ions. However, few studies have examined the systematic research on the adsorption behavior between the crystallinity of HAp and various types of proteins.

In the present study, we report on the synthesis of HAp nanoparticles (nano-HAp) controlling both the crystalline and morphological features by changing the $\mathrm{pH}$ and synthesis temperature; moreover, we discuss in detail the relationship between the HAp particle characteristics and the proteins adsorbed on the HAp.

\section{Experimental procedure}

\subsection{Materials}

All materials were of analytical grade and used as received without further purification. Calcium nitrate tetrahydrate [Ca$\left.\left(\mathrm{NO}_{3}\right)_{4} \cdot 4 \mathrm{H}_{2} \mathrm{O}\right]$, diammonium hydrogen phosphate $\left[\left(\mathrm{NH}_{4}\right)_{2} \mathrm{HPO}_{4}\right]$, aqueous ammonia $\left(\mathrm{NH}_{4} \mathrm{OH}\right)$, and acetone was procured from Wako Pure Chemical Industries, Japan. BSA (isoelectric point $(\mathrm{pI})=4.7$, molecular weight $(\mathrm{MW})=66000$, an acidic protein $)$, myoglobin (MGB: $\mathrm{pI}=7.0, \mathrm{MW}=18000$, a neutral protein), and lysozyme (LSZ: $\mathrm{pI}=11.1, \mathrm{MW}=15000$, a basic protein) were purchased from Sigma-Aldrich (St. Louis, MO). 


\subsection{Preparation of nano-HAp by a hydrothermal method}

Nano-HAp was prepared from mixture of a $0.05 \mathrm{M}$ solution of $\mathrm{Ca}\left(\mathrm{NO}_{3}\right)_{4} \cdot 4 \mathrm{H}_{2} \mathrm{O}$ and a $0.03 \mathrm{M}$ solution of $\left(\mathrm{NH}_{4}\right)_{2} \mathrm{HPO}_{4}$ by a hydrothermal method. A $200-\mathrm{mL} 0.03 \mathrm{M}\left(\mathrm{NH}_{4}\right)_{2} \mathrm{HPO}_{4}$ solution was added to $200 \mathrm{~mL}$ of the $0.05 \mathrm{M} \mathrm{Ca}\left(\mathrm{NO}_{3}\right)_{4} \cdot 4 \mathrm{H}_{2} \mathrm{O}$ solution. The mixture was subsequently stirred for $5 \mathrm{~min}$ at $20^{\circ} \mathrm{C}$ and further stirred at $25,60,120$, or $180^{\circ} \mathrm{C}$, respectively. The reaction temperature was increased at the rate of $1^{\circ} \mathrm{C} / \mathrm{min}$ and the mixture was stirred at each temperature for another $3 \mathrm{~h}$ under hydrothermal conditions. The products were recovered by filtration, washed repeatedly with distilled water, and dried at $60^{\circ} \mathrm{C}$ overnight; the obtained samples were abbreviated as $\mathrm{CP}-1\left(25^{\circ} \mathrm{C}\right), \mathrm{CP}-2$ $\left(60^{\circ} \mathrm{C}\right), \mathrm{CP}-3\left(120^{\circ} \mathrm{C}\right)$, and $\mathrm{CP}-4\left(180^{\circ} \mathrm{C}\right)$, respectively. Under other conditions, both the calcium and phosphate solutions were adjusted to $\mathrm{pH} 10$ using aqueous ammonia before mixing, and then the procedure was the same as described above. The products of the $\mathrm{pH}$-adjusted conditions were abbreviated as $\mathrm{pHCP}-1$, pHCP-2, pHCP-3, and pHCP-4, respectively.

\subsection{Characterization of synthesized nano-HAp}

All the particles prepared were characterized by nitrogen gas adsorption/desorption isotherms at $77 \mathrm{~K}$ using a TriStar 3000 system (Shimadzu Co., Japan). Samples were preheated at $120^{\circ} \mathrm{C}$ under vacuum for $2 \mathrm{~h}$ to remove bound water. Specific surface areas were measured using the Brunauer-Emmett-Teller (BET) method. Powder X-ray diffraction (XRD) analysis was performed using a RINT2000/PC (Rigaku Co., Japan) model using a $\mathrm{Cu} \mathrm{K} \alpha$ source. The $2 \theta$ scanning range was set between 3 and $60^{\circ}$; generator settings were $40 \mathrm{kV}$ and $30 \mathrm{~mA}$. Field emission-scanning electron microscopy (FE-SEM, S-3000 instrument operated at $20 \mathrm{kV}$, Hitachi Co., Japan) was used to study the morphology of the particles. Before observation, the samples were coated (spluttered) with platinum using a Hitachi E-1020 ion sputter. The molar ratio of $\mathrm{Ca} / \mathrm{P}$ was measured by inductively coupled plasma-atomic emission spectrometry (IRIS Advantage, NIPPON THERMO Co., Japan). The $\zeta$-potential of particles was measured using an ELSZ-2 zeta potential analyzer (Ohtsukadensi Co., Japan).

\subsection{Protein adsorption on nano-HAp}

Protein adsorption was performed using BSA as an acidic protein, MGB as a neutral protein, and LSZ as a basic protein. ${ }^{26), 27)}$ Five $\mathrm{mg}$ of nano-HAp particles was mixed in $1 \mathrm{~mL}$ of a 0.5 $\mathrm{mg} / \mathrm{mL}$ protein solution dissolved in $11 \mathrm{mM}$ of a phosphate buffer solution ( $\mathrm{pH} 7.4)$. The mixture was stirred overnight at $4^{\circ} \mathrm{C}$. After being centrifuged at 12000 r.p.m. for $10 \mathrm{~min}$, the amount of unadsorbed protein in the supernatant was determined by the Bradford protein assay using the absorption band at $595 \mathrm{~nm}^{28)}{ }^{29)}$ The amount of proteins adsorbed on the nano-HAp was calculated from the amount of proteins in the supernatant.

\section{Results and discussion}

\subsection{Properties of HAp particles}

Figure 1 shows the XRD patterns of the products prepared with different $\mathrm{pH}$ values and at various temperatures. The peaks associated with dicalcium phosphate dihydrate (DCPD) were observed in the pattern for $\mathrm{CP}-1$ synthesized at $25^{\circ} \mathrm{C}$ (nonadjusted $\mathrm{pH}$-approximately $\mathrm{pH}$ 6) [Fig. 1(a)]. In the products synthesized at temperatures above $60^{\circ} \mathrm{C}(\mathrm{CP}-2, \mathrm{CP}-3, \mathrm{CP}-4)$ under non-pH-adjusted conditions, all the peaks were assigned to HAp (JCPDS: 9-432). The broad XRD peaks for CP-2 suggest that the product synthesized at $60^{\circ} \mathrm{C}$ was an incompletely (a)

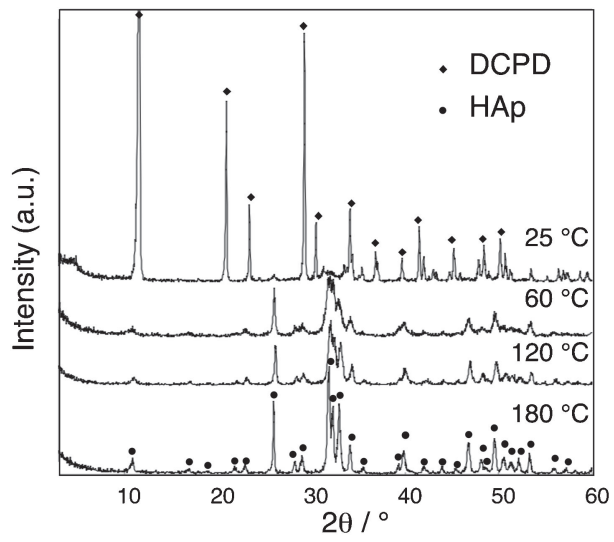

(b)

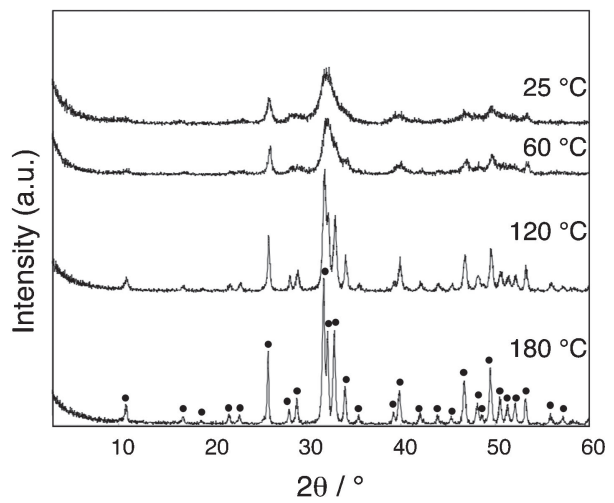

Fig. 1. XRD patterns of the products synthesized at various temperatures: (a) the products prepared under non-adjusted $\mathrm{pH}$ conditions. (b) The products prepared under $\mathrm{pH} 10$ conditions.

crystallized hydroxyapatite. Increasing the temperature caused the peaks to sharpen, which indicates that the crystallinity of the products (CP-3, CP-4) improved. ${ }^{30)}$ The XRD patterns of the all products synthesized at $\mathrm{pH} 10$ (pHCP-1, pHCP-2, pHCP-3, pHCP-4) showed a good agreement with HAp [Fig. 1(b)]. The broad XRD peaks for $\mathrm{pHCP}-1$ and $\mathrm{pHCP}-2$ showed that the product crystallinity was low. The peaks for $\mathrm{pHCP}-3$ and $\mathrm{pHCP}-4$ became increasingly sharper with increasing synthesis temperature, indicating an improvement in the crystalline nature of the products.

The morphologies of the products are shown by FE-SEM in Fig. 2. The image for $\mathrm{CP}-1$ shows plate-like particles of 5-20 $\mu \mathrm{m}$ width, which is a characteristic morphology of DCPD [Fig. 2(a)]. The images for CP-2, CP-3, and CP-4 revealed rod-like crystals of $50 \mathrm{~nm}$ width and 190,220, and $270 \mathrm{~nm}$ length, respectively, indicating that the crystals grew along the $c$-axis with increasing temperature [Fig. 2(a)]. The image for $\mathrm{pHCP}-1$ shows large agglomerates formed by the aggregation of smaller particles [Fig. 2(b)]. The images for pHCP-2, pHCP-3, and pHCP-4 show granule-like particles with aspect ratios of $c a .1$ and 30,50, and $75 \mathrm{~nm}$ size, respectively [Fig. 2(b)].

The results from the XRD and FE-SEM indicate that in the case of non-pH-adjusted conditions, DCPD was obtained at a synthesis temperature of $25^{\circ} \mathrm{C}$ and $\mathrm{HAp}$ nanoparticles were obtained at over $60^{\circ} \mathrm{C}$. Moreover, we found that HAp nanoparticles were growing along the $c$-axis as the synthesis temperature increased. However, at $\mathrm{pH}$ 10, HAp nanoparticles were obtained at all temperatures studied; moreover, the HAp nanoparticles exhibited a similar aspect ratio ( $c a .1)$ that was independent of the synthesis temperature. These results imply that the high $\mathrm{pH}$ 
value induced HAp nucleation before heat treatment and prevented the anisotropic growth of HAp during heat treatment. In addition, each product synthesized (CP-2, CP-3, CP-4, pHCP-1, pHCP-2, pHCP-3 and pHCP-4) can be referred to as nano-HAp.

Some of the properties of the products evaluated by BET, $\zeta$-potential, and $\mathrm{Ca} / \mathrm{P}$ molar ratio are summarized in Table 1. The surface charge is an important property in protein adsorption since it influences the electrostatic interaction between the protein and the nano-HAp surface. The $\zeta$-potential of all the products

(a)
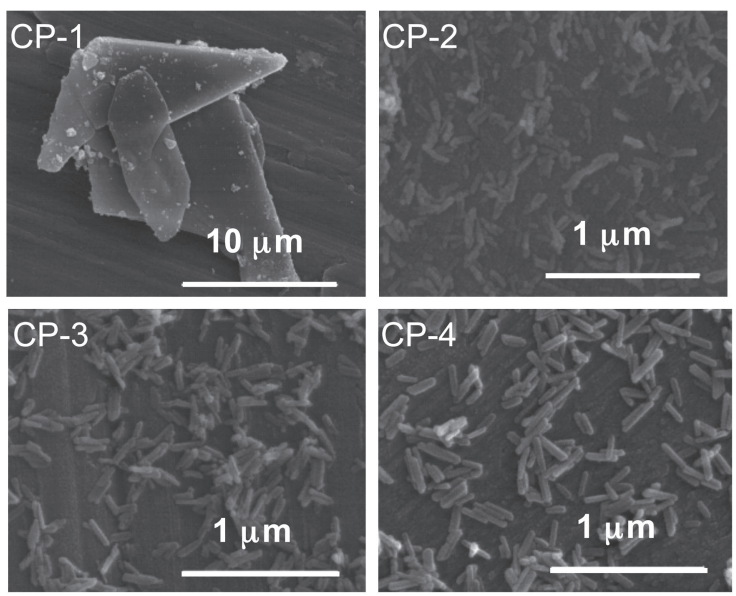

(b)
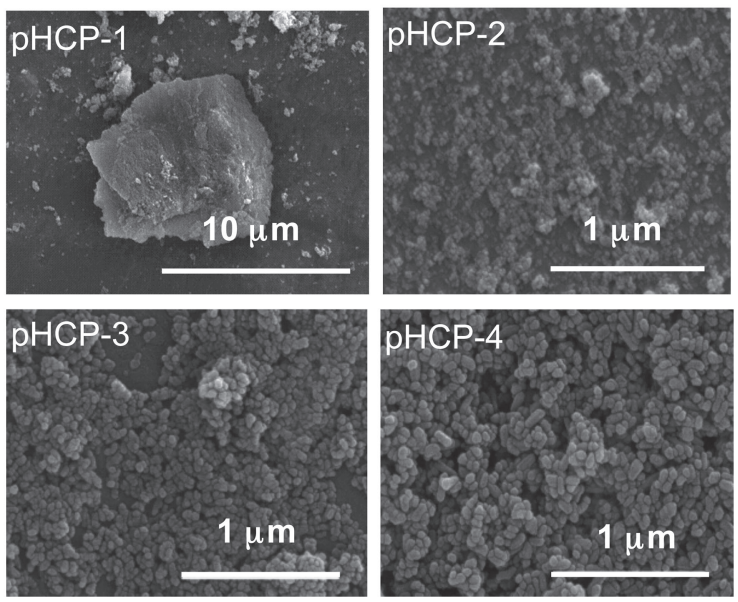

Fig. 2. SEM images of the products (a) prepared at non-adjusted $\mathrm{pH}$ and (b) prepared at $\mathrm{pH} 10$. were found to exhibit negative charges, ranging from -19.2 to $-34.3 \mathrm{mV}$ in phosphate buffer solution ( $\mathrm{pH}$ 7.4). Moreover, the $\zeta$-potential tended to decrease as the synthesis temperature increased. The specific surface area measured by BET decreased with increasing synthesis temperature for the nano-HAps synthesized over $60^{\circ} \mathrm{C}$, which is consistent with the morphological observation by FE-SEM. The $\mathrm{Ca} / \mathrm{P}$ molar ratios of nano-HAp synthesized under the non-adjusted $\mathrm{pH}$ condition (CP-2, CP-3, CP-4) ranged from 1.50 to 1.62 , indicating that CP-2, CP-3 and CP-4 were calcium-deficient HAp. Increasing the temperature caused an increase of the $\mathrm{Ca} / \mathrm{P}$ molar ratio in nano-HAp. However, the $\mathrm{Ca} / \mathrm{P}$ molar ratios of nano-HAps synthesized at pH 10 over $60^{\circ} \mathrm{C}$ (pHCP-2, pHCP-3, pHCP-4) exhibited comparable ratios to the theoretical value 1.67 , indicating that these nano-HAps were approximately stoichiometric, while pHCP-1 synthesized at $25^{\circ} \mathrm{C}$ was a calcium-deficient HAp.

\subsection{Adsorption of proteins onto nano-HAps}

The results of the protein adsorption onto nano-HAp are shown in Fig. 3. The amount of protein adsorbed onto nanoHAps synthesized under the non-adjusted condition (CP-2, CP-3, and $\mathrm{CP}-4$ ) showed that LSZ adsorption slightly increased and MGB adsorption slightly decreased with an increasing synthesis temperature. However, the amount of BSA exhibited no marked tendency for the synthesis temperatures. It has been reported that various properties of HAp, such as surface charge, $\mathrm{Ca} / \mathrm{P}$ molar ratio, substitution content, or morphology, affect the amount of adsorbed proteins. Because CP-2, CP-3, and CP-4 have different crystal properties individually, the improvement in LSZ adsorption might be due to the increase in electrostatic interactions between nano-HAp and LSZ, but the influence of other factors, such as the $\mathrm{Ca} / \mathrm{P}$ molar ratio or morphology, cannot be ignored.

In contrast, nano-HAps synthesized at $\mathrm{pH} 10$ over $60^{\circ} \mathrm{C}$ (pHCP-2, pHCP-3 and pHCP-4) have approximately stoichiometric values of $\mathrm{Ca} / \mathrm{P}$ (1.66-1.67), and a similar aspect ratio in their morphology (length/width is $c a$. 1). Therefore, the adsorption behavior of the proteins can be estimated by the crystallinity and $\zeta$-potential of the nano-HAps. The adsorbed amount of LSZ onto pHCP-2, pHCP-3, and pHCP-4 showed, remarkably, an increase with increasing synthesis temperature. This result can be explained by the following two assumptions; (i) the basic protein, LSZ, having a positive charge in the phosphate buffer solution at $\mathrm{pH} 7.4$ adsorbed by electrostatic interaction on the HAp surface that had a more negative $\zeta$-potential; (ii) the improvement in the crystalline nature of the nano-HAps promoted the adsorption of the basic protein on the P-sites, because nano-HAps with high crystallinity would expose their clear crystal faces close to the theoretical $a$ - and $c$-face, which originated from the regulated

Table 1. Synthesis conditions and properties of the products prepared in this study

\begin{tabular}{ccccccc}
\hline & $\begin{array}{c}\text { Synthesis temperature } \\
\left({ }^{\circ} \mathrm{C}\right)\end{array}$ & $\mathrm{pH}$ & $\begin{array}{c}\text { Specific surface area }{ }^{\mathrm{a})} \\
\left(\mathrm{m}^{2} / \mathrm{g}\right)\end{array}$ & $\mathrm{Ca} / \mathrm{P}^{\mathrm{b})}$ & $\begin{array}{c}\zeta \text {-potential }^{\mathrm{c})} \\
(\mathrm{mV})\end{array}$ & $\begin{array}{c}\mathrm{Crystal} \\
\mathrm{phase}^{\mathrm{d})}\end{array}$ \\
\hline $\mathrm{CP}-1$ & 25 & $--^{*}$ & 16.9 & 1.11 & -19.2 & DCPD \\
CP-2 & 60 & $--^{*}$ & 84.3 & 1.50 & -23.5 & HAp \\
CP-3 & 120 & $--^{*}$ & 64.0 & 1.57 & -28.0 & HAp \\
CP-4 & 180 & 10 & 39.7 & 1.62 & -32.2 & HAp \\
pHCP-1 & 25 & 10 & 106.3 & 1.54 & -26.3 & HAp \\
pHCP-2 & 60 & 10 & 59.8 & 1.67 & -25.8 & HAp \\
pHCP-3 & 120 & 10 & 35.1 & 1.67 & -33.4 & HAp \\
pHCP-4 & 180 & & 1.66 & -34.3 & HAp \\
\hline
\end{tabular}

* prepared under non-pH-adjusted conditions. a) Specific surface area by BET method. b) Ca/P molar ratio by ICP-AES.

c) Surface potential of particles. d) Crystalline phase confirmation by XRD analysis. 
(a)

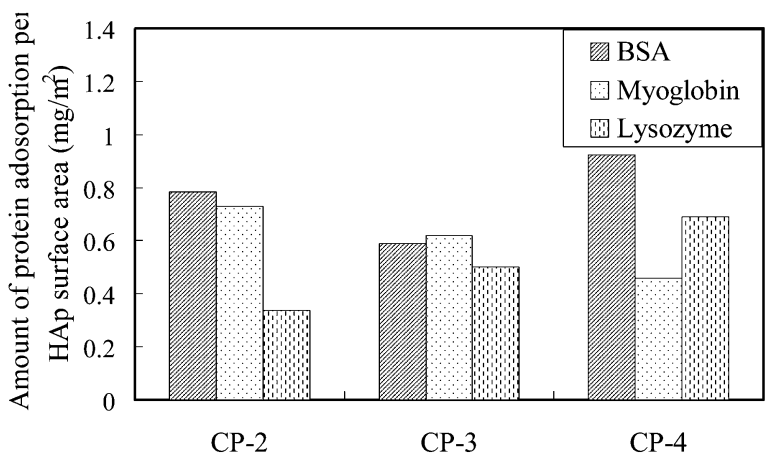

(b)

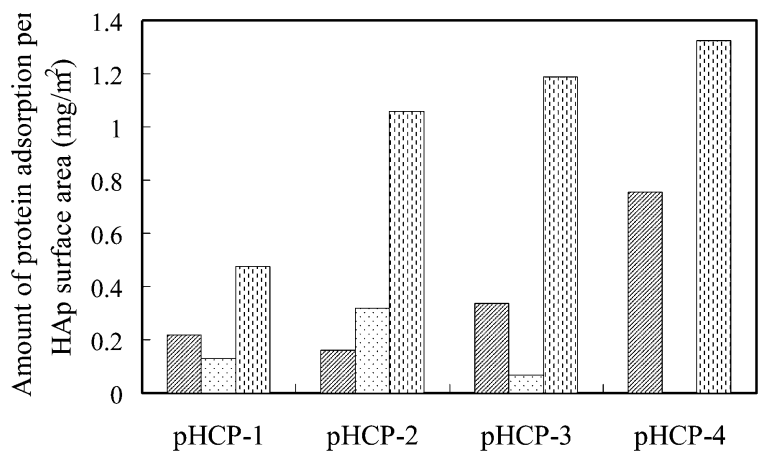

Fig. 3. Protein adsorption behavior of nano-HAp prepared (a) in non$\mathrm{pH}$-adjusted solutions and (b) in $\mathrm{pH}$-adjusted solutions.

atomic arrangement. It is noteworthy that the adsorbed amount of acidic protein, $\mathrm{BSA}$ onto $\mathrm{pHCP}-2$, $\mathrm{pHCP}-3$, and $\mathrm{pHCP}-4$ also exhibited a tendency similar to that of LSZ, increasing with an increasing synthesis temperature. Since BSA has a negative charge in phosphate buffer solution at $\mathrm{pH} 7.4$, this increase of adsorbed BSA cannot be described by the $\zeta$-potential of nanoHAps. Kandori et al. have reported that the C-site on HAp has a high adsorption affinity for BSA; nevertheless, the net surface charge of HAp is negative. ${ }^{5), 26)}$ Therefore, this increase of the adsorbed BSA can be attributed to the improvement in the crystalline nature of nano-HAps, that is, the highly regulated atomic arrangement of HAp surface readily adsorbed acidic protein, despite the negative total surface charges. In contrast, the adsorbed amount of neutral protein, MGB onto pHCP-2, pHCP3 , and pHCP-4 shows the adsorption tendency opposite to that of LSZ and BSA, decreasing from $0.30 \mathrm{mg} / \mathrm{m}^{2}$ to almost zero with an increasing synthesis temperature. This result may seem certainly logical because the two different binding sites (C- and P-site) on the HAp surface have specific adsorption abilities for acidic proteins and basic proteins, respectively, so neither of the two sites would prefer to adsorb the neutral protein, MGB. However, it has been reported that MGB can adsorb onto HAp. ${ }^{26)}$ Actually, MGB adsorption onto nano-HAp (e.g. CP-4) has also been described in this paper. When compared with the other nano-HAps, the characteristic crystal properties of pHCP-4 were high crystallinity and the approximately stoichiometric $\mathrm{Ca} / \mathrm{P}$ molar ratio. These results suggested that the theoretical HAp crystal having high crystallinity and a stoichiometric atomic ratio would have little affinity for the neutral protein, MGB. On the basis of the above results, we can summarize as follows: the improvement of the crystallinity of HAp resulted in the high adsorption ability for the acidic protein BSA and the basic protein LSZ. Moreover, it was found that the nearly stoichiometric crystals of HAp had little affinity for the neutral protein, MGB, which can be explained by the specific interaction between the $C$ and P-sites on HAp and the acidic proteins and basic proteins, respectively and these would be dominant over other factors, such as electrostatic interactions.

\section{Conclusion}

The effects of HAp crystallinity on the protein adsorption were examined. HAp nanoparticles (nano-HAp) were synthesized using a hydrothermal method with varying synthesis temperatures and $\mathrm{pH}$ conditions. Nano-HAps obtained over $60^{\circ} \mathrm{C}$ and $\mathrm{pH} 10$ had similar aspect ratios in their morphology (length/ width $c a$. 1) and approximately stoichiometric $\mathrm{Ca} / \mathrm{P}$ molar ratios. The nano-HAps merely altered their crystallinity and $\zeta$-potential by varying the synthesis temperatures. The adsorption amounts of proteins onto the nano-HAps revealed that the improvement in the crystallinity of HAp elevated the adsorption ability for both the acidic protein BSA and the basic protein LSZ. In contrast, we found a decreased adsorption affinity to neutral protein, MGB. This unique adsorption behavior can be explained by the specific binding of the $\mathrm{C}$ - or P-site on HAp towards acidic or basic proteins, respectively. These results suggest that the adsorption behavior between various types of proteins and HAp with high crystallinity is strongly affected by HAp's specific binding sites.

\section{References}

1) S. V. Dorozhkin, J. Mater. Sci., 15, 2343-2387 (2009).

2) S. V. Dorozhkin, Materials, 2, 1975-2045 (2009).

3) C. Ohtsuki, T. Ichikawa, H. Shibata, G. Kawachi, T. Torimoto and S. Ogata, J. Mater. Sci.: Mater. Med., 21, 1225-1232 (2010).

4) T. Matsumoto, M. Okazaki, M. Inoue, S. Tamaguchi, T. Kusunose, T. Toyonaga, Y. Hamada and J. Takahashi, Biomaterials, 25, 3807-3812 (2004).

5) K. Kandori, S. Mizumoto, S. Toshima, M. Fukusumi and Y. Morisada, J. Phys. Chem. B, 113, 11016-11022 (2009).

6) F. Nagata, T. Miyajima and Y. Yokogawa, J. Eur. Ceram. Soc., 26, 533-535 (2006).

7) T. Kawasaki, J. Chromatogr. A, 544, 147-184 (1991).

8) D. T. H. Wassell, R. C. Hall and G. Embery, Biomaterials, 16, 697-702 (1995).

9) M. R. Mucalo, K. Kato and Y. Yokogawa, Colloids Surf., B: Biointerfaces, 71, 52-58 (2009).

10) T. Yokoi, M. Kawashita, K. Kikuta and C. Ohtsuki, J. Cryst. Growth, 312, 2376-2382 (2010).

11) R. Ramachandra Rao, H. N. Roopa and T. S. Kannan, J. Mater. Sci.: Mater. Med., 8, 511-518 (1997).

12) S. H. Rhee and J. Tanaka, J. Am. Ceram. Soc., 81, 3029-3031 (1998).

13) A. Jillavenkatesa and R. A. Condrate, Sr., J. Mater. Sci., 33, 4111-4119 (1998).

14) H. K. Varma, S. N. Kalkura and R. Sivakumar, Ceram. Int., 24, 467-470 (1998).

15) K. Yamashita, T. Arashi, K. Kitagaki, S. Yamada and T. Umegaki, J. Am. Ceram. Soc., 77, 2401-2407 (1994).

16) M. Yoshimura, H. Suda, K. Okamoto and K. Ioku, J. Mater Sci., 29, 3399-3402 (1994).

17) F. Nagata, M. Toriyama, K. Teraoka and Y. Yokogawa, Chem. Lett., 8, 780-781 (2001).

18) I. S. Neira, Y. V. Kolen'ko, O. I. Lebedev, G. Van Tendeloo, H. S. Gupta, F. Guitian and M. Yoshimura, Cryst. Growth Des., 
9, 466-474 (2009).

19) K. Kandori, M. Saito, T. Takebe, A. Yasukawa and T. Ishikawa, Colloid Surf. B-Biointerfaces, 5, 81-87 (1995).

20) K. Kandori, S. Tsuyama, H. Tanaka and T. Ishikawa, Colloids Surf., B: Biointerfaces, 58, 98-104 (2007).

21) K. Kandori, S. Oda and S. Tsuyama, J. Phys. Chem. B, 112, 2542-2547 (2008).

22) G. Kawachi, S. Sasaki, K. Nakahara, E. H. Ishida and K. Ioku, Key Eng. Mater., 309-311, 935-938 (2006).

23) T. Takahashi, M. Kamitakahara, G. Kawachi and K. Ioku, Key Eng. Mater, 361-363, 83-86 (2008).

24) E. Fujii, M. Ohkubo, K. Tsuru, S. Hayakawa, A. Osaka, K. Kawabata, C. Bonhomme and F. Babonneau, Acta Biomater. 2, 69-74 (2006).
25) S. Dasgupta, S. S. Banerjee, A. Babdyopadhyay and S. Bose, Langmuir, 26, 4958-4964 (2010).

26) K. Kandori, A. Fudo and T. Ishikawa, Phys. Chem. Chem. Phys., 2, 2015-2020 (2000).

27) Y. Yokogawa, F. Nagata, K. Kato, Y. Shiotsu and M. Watanabe, J. Eur. Ceram. Soc., 26, 519-523 (2006).

28) N. Carlsson, A. Borde, S. Wolfel, B. Akemann and A. Larsson, Anal. Biochem., 411, 116-121 (2011).

$29)$ S. C. Silverio, S. Moreira, A. M. F. Milagres, E. A. Macedo, J. A. Teixeira and S. I. Mussatto, Anal. Biochem., 421, 719724 (2012).

30) N. Puvvada, P. K. Panigrahi and A. Pathak, Nanoscale, 2, 2631-2638 (2010). 